\title{
Mitochondrial Fatty Acid $\beta$-Oxidation in the Retinal Pigment Epithelium
}

\author{
TIINA TYNI, MARGARET JOHNSON, SIMON EATON, MORTEZA POURFARZAM, \\ RICHARD ANDREWS, AND DOUGLASS M. TURNBULL
}

Department of Neurology [T.T., M.J., D.M.T.], Department of Ophthalmology [R.A.], University of Newcastle upon Tyne, U.K.; James Spence Institute of Child Health, Royal Victoria Infirmary, Newcastle upon Tyne, U.K. [M.P.]; Unit of Paediatric Surgery, Institute of Child Health, London, U.K. [S.E.]; Hospital for Children and Adolescents, Helsinki, Finland [T.T.]

\begin{tabular}{|c|c|}
\hline \multicolumn{2}{|c|}{ ABSTRACT } \\
\hline $\begin{array}{l}\text { Pigmentary retinopathy is an important feature of long-chain } \\
\text { 3-hydroxyacyl-CoA dehydrogenase (LCHAD) deficiency, a dis- } \\
\text { order of mitochondrial fatty acid } \beta \text {-oxidation. Pathogenesis of } \\
\text { this complication remains unknown. The retinal pigment epithe- } \\
\text { lium (RPE) is affected early in this retinopathy. We wanted to } \\
\text { determine whether there is evidence of mitochondrial fatty acid } \\
\beta \text {-oxidation in the RPE cells. Fatty acid oxidation was measured } \\
\text { from cultured porcine RPE cells by incubating them with } \\
{\left[\mathrm{U}-{ }^{13} \mathrm{C}\right] \text {-hexadecanoic acid. Acylcarnitine esters were analyzed }} \\
\text { by tandem mass spectrometry. The activity of LCHAD and } \\
\text { carnitine uptake capacity were measured from the cultured cells. } \\
\text { Antibodies to the human mitochondrial trifunctional protein } \\
\text { (MTP) containing LCHAD activity were used to analyze the } \\
\text { expression of the MTP in the cultured RPE cell lysate and in } \\
\text { human retinal sections by immunoblotting and immunohisto- } \\
\text { chemistry. Fatty acid oxidation analysis showed normal chain } \\
\text { shortening of hexadecanoic acid and production of acetylcarni- } \\
\text { tine in cultured RPE cells. Immunoblotting revealed expression } \\
\text { of the MTP and enzyme assay showed the activity of LCHAD in }\end{array}$ & $\begin{array}{l}\text { the RPE cells. RPE cells were also capable of carnitine uptake. } \\
\text { Positive labeling to the MTP antibodies was detected in the RPE, } \\
\text { photoreceptors, and ganglion cells. The results give strong in } \\
\text { vitro evidence for the presence of mitochondrial fatty acid } \beta \text {-ox- } \\
\text { idation in RPE cells and the expression of the MTP in the RPE } \\
\text { and other layers of the retina. Further studies are required to } \\
\text { clarify whether this pathway acts also in vivo in the retina. } \\
\text { (Pediatr Res 52: 595-600, 2002) } \\
\text { Abbreviations } \\
\text { DAB, 3,3'-diaminobenzidine tetrahydrochloride } \\
\text { RHA, docosahexaenoic acid } \\
\text { LC, long chain } \\
\text { LCHAD, long-chain 3-hydroxyacyl-CoA dehydrogenase } \\
\text { MEM, minimum essential medium } \\
\text { MTP, mitochondrial trifunctional protein } \\
\text { RPE, retinal pigment epithelium } \\
\text { SC, short chain }\end{array}$ \\
\hline
\end{tabular}

In a defect of mitochondrial fatty acid $\beta$-oxidationLCHAD (MIM \#600890) deficiency_pigmentary retinopathy is the major complication (1). Although the enzyme defect and disease-causing mutations of LCHAD deficiency are well characterized, pathogenesis of ocular manifestations remains unknown. Treatment of systemic manifestations of this disorder does not necessarily prevent progression of the retinopathy, potentially leading to blindness. Therefore, understanding the pathogenesis of ocular manifestations is essential.

$\beta$-Oxidation is a major energy-producing pathway of metabolically active tissues such as skeletal muscle and heart. The

Received January 9, 2002; accepted March 21, 2002.

Correspondence: Tiina Tyni, Hospital for Children and Adolescents, University of Helsinki, P.O.B. 280, FIN-00029 HUS, Helsinki, Finland; e-mail: Tiina.Tyni@hus.fi

Supported by the Juselius Foundation, Helsinki, Finland; the Arvo and Lea Ylppö Foundation, Espoo, Finland; and the Ulla Hjelt Trust, The Pediatric Research Foundation, Helsinki, Finland; and the Wellcome Trust, London, U.K.

DOI: 10.1203/01.PDR.0000030874.20888.2D liver can convert acetyl-CoA produced by mitochondrial $\beta$-oxidation to ketone bodies (acetoacetate and $\beta$-hydroxybutyrate) for the use of other tissues not capable of $\beta$-oxidation. LCHAD is one of three enzyme activities of the MTP; the other two activities being long-chain 2-enoyl-CoA hydratase and 3-ketoacyl-CoA thiolase (MIM \#143450). These enzymes are required for the three last steps of a single $\beta$-oxidation cycle for long-chain fatty acids. There are two forms of MTP deficiency: isolated LCHAD deficiency, in which the activity of LCHAD is deficient but those of long-chain 2-enoyl-CoA hydratase and 3-ketoacyl-CoA thiolase are essentially normal, and trifunctional protein deficiency, in which there is a complete absence of immunoreactive protein for both subunits (and, therefore, deficiency of all three enzyme activities) of the MTP (2). Of two main forms of MTP deficiency, pigmentary retinopathy seems to be typical of isolated LCHAD deficiency (1). The natural course of LCHAD deficiency often results in death in infancy or childhood. Therapy with a high-carbohydrate, low- 
fat diet and avoidance of fasting can prevent the progression of systemic manifestations, but is not necessarily effective in the treatment of pigmentary retinopathy and peripheral neuropathy $(3,4)$.

Association of a mitochondrial fatty acid $\beta$-oxidation defect with retinopathy is surprising because, as in the brain, glucose is considered to be the primary source of energy in the whole retina (5). Clinical and histopathological findings in retinopathy of LCHAD deficiency suggest that both the choriocapillaris and RPE cells are affected early in its course (6). Detection of low levels of the essential fatty acid DHA in the plasma of a patient with LCHAD retinopathy led to a hypothesis that DHA deficiency is a causative factor in the retinopathy associated with LCHAD deficiency (7). However, DHA deficiency is not a consistent finding in patients with this retinopathy (unpublished observation).

No studies are available on the presence of mitochondrial fatty acid $\beta$-oxidation in RPE cells or its possible role in RPE cell metabolism. We studied mitochondrial fatty acid $\beta$-oxidation in cultured porcine RPE cells and human retinal sections to further elucidate the energy metabolism of these cells and the pathogenesis of pigmentary retinopathy in LCHAD deficiency.

\section{MATERIALS AND METHODS}

\section{Cell Culture}

Porcine RPE cells were isolated by a modification of the method by Edwards (8). Briefly, enucleated eyes were soaked in PBS solution containing $0.1 \mathrm{mg} / \mathrm{mL}$ of streptomycin and 100 $\mathrm{U} / \mathrm{mL}$ of penicillin. The anterior section of the eye was removed and the vitreous humor aspirated. The remaining neural retina was removed with forceps. Exposed RPE cells were trypsinized $(0.25 \%$ trypsin, $0.02 \%$ EDTA in PBS), incubating the eyecup at $37^{\circ} \mathrm{C}$ for $3 \times 30 \mathrm{~min}$. Dissociated RPE cells were aspirated and seeded into $12.5 / 25 \mathrm{~cm}^{2}$ tissue culture flasks. The cells were cultured in Ham's F-10 culture medium (Invitrogen, Carlsbad, CA, U.S.A.) supplemented with $10 \%$ (vol/vol) fetal bovine serum, $0.1 \mathrm{mg} / \mathrm{mL}$ of streptomycin, and $100 \mathrm{U} / \mathrm{mL}$ of penicillin. The medium was exchanged every $3-4$ d. The cultured cells were pigmented, and their morphology was similar to that described in previous reports on RPE cell culture $(9,10)$.

Fibroblasts were cultured in MEM supplemented with $10 \%$ (vol/vol) fetal bovine serum, 1\% (vol/vol) MEM essential amino acids, $1 \%$ (vol $/ \mathrm{vol}$ ) MEM vitamins, and $0.1 \mathrm{mg} / \mathrm{mL}$ streptomycin and $100 \mathrm{U} / \mathrm{mL}$ of benzylpenicillin.

\section{Fatty Acid Oxidation Studies}

Measurement of fatty acid oxidation. Fatty acid $\beta$-oxidation was studied by incubating the RPE cells with $\left[\mathrm{U}-{ }^{13} \mathrm{C}\right]-$ hexadecanoic acid (Cambridge Isotope Laboratories, Andover, MA, U.S.A.) (11). In essence, for incubation, RPE cells $(n=$ 3) from two $75-\mathrm{cm}^{2} 80-90 \%$ confluent flasks were harvested with trypsin, resuspended in fatty acid incubation medium (12), and homogenized with a pellet pestle (Sigma Chemical, Poole, Dorset, U.K.). Samples were taken after 30, 60, and $90 \mathrm{~min}$ incubation. The samples were combined with stable, isotopically labeled internal standards, extracted with methanol, and run through Sephadex columns (Amersham Pharmacia Biotech U.K., Little Chalfont, Buckinghamshire, U.K.). After drying, the sample was derivatized with HCl-butanol. The butyl esters of acylcarnitines were analyzed with tandem mass spectrometry (Quattro II tandem quadrupole mass spectrometer, Micromass, Altrincham, U.K.). Intensities of the intermediates were referenced to intensities of the internal standards and citrate synthase activity measured from the cell homogenate (13).

Measurement of enzyme activities. LCHAD and 3-ketoacylCoA thiolase activities were measured in cultured RPE cells from two $75-\mathrm{cm}^{2}$ flasks, essentially as previously described (14). RPE cell pellets were resuspended in $25 \mathrm{mM}$ phosphate, $0.2 \mathrm{mM}$ EDTA, and $0.4 \% \mathrm{vol} / \mathrm{vol}$ Triton X-100, $\mathrm{pH} 8$, and incubated on ice for $30 \mathrm{~min}$. After centrifugation $(11,600 \times g$ for $10 \mathrm{~min}$ ), 3-hydroxyacyl-CoA dehydrogenase activity was measured in the reverse direction in the supernatant by following the disappearance of NADH at $340 \mathrm{~nm}$. The reaction medium consisted of $0.1 \mathrm{M}$ potassium phosphate, $\mathrm{pH}$ 7.0/0.1 $\mathrm{mg} / \mathrm{mL} \mathrm{NADH} / 0.3 \mathrm{mg}$ BSA (fatty acid free), plus $40 \mu \mathrm{M}$ acetoacetyl-CoA (short chain) or 3-ketohexadecanoyl-CoA. Long-chain and short-chain 3-ketoacyl-CoA thiolase activities were measured in the same supernatant at $303 \mathrm{~nm}$ and $30^{\circ} \mathrm{C}$ as the rate of cleavage of 3-ketohexadecanoyl-CoA or acetoacetyl-CoA $(10 \mu \mathrm{M})$ in $50 \mathrm{mM}$ Bis-Tris-propane and $2 \mathrm{mM}$ $\mathrm{MgCl}_{2}, \mathrm{pH} 9.0$, in the presence of $0.2 \mathrm{mg} / \mathrm{mL} \mathrm{CoASH}$. The measurements were performed in duplicate.

Carnitine uptake analysis. Carnitine uptake by cultured RPE cells was measured with radiolabeled carnitine using a modification of the method described by Treem et al. (15) for fibroblasts. Carnitine uptake in the RPE cells was compared with that in fibroblasts. RPE cells and fibroblasts from two cells lines were grown to confluence in six-well plates $(9.5$ $\mathrm{cm}^{2} /$ well).

The culture medium of RPE cells and fibroblasts was changed to RPMI 1640 (Invitrogen) $24 \mathrm{~h}$ before the uptake study. After washing the monolayer thoroughly with PBS, the cells were incubated in $1 \mathrm{~mL}$ of RPMI 1640 containing $0.5 \mu \mathrm{L}$ of methyl- $\left[{ }^{3} \mathrm{H}\right]$-carnitine, (specific activity $3.11 \mathrm{TBq} / \mathrm{mmol}$ ) (Amersham Pharmacia Biotech U.K.) and different concentrations of unlabeled L-carnitine (Sigma Chemical) for $4 \mathrm{~h}$ at $37^{\circ} \mathrm{C}$ in humidified $5 \% \mathrm{CO}_{2} / 95 \%$ air. Fibroblasts were incubated with $0.5 \mu \mathrm{L}$ of methyl- $\left[{ }^{3} \mathrm{H}\right]$-carnitine and several concentrations $(0.5-50 \mu \mathrm{M})(n=3$ for each carnitine concentration) of unlabeled L-carnitine. RPE cells were incubated with $0.5 \mu \mathrm{L}$ of methyl- $\left[{ }^{3} \mathrm{H}\right]$-carnitine and $0.5 \mu \mathrm{M}, 1.0 \mu \mathrm{M}$, and $5 \mu \mathrm{M}(n=3$ for each carnitine concentration) of unlabeled L-carnitine. Concentration of $50 \mathrm{mM}$ unlabeled carnitine was used to determine nonspecific binding of L-carnitine. After incubation, the cells were washed four times with PBS and hydrolyzed with $1 \mathrm{~mL}$ $0.5 \mathrm{M} \mathrm{NaOH}$. Radioactivity was determined in $800 \mu \mathrm{L}$ of the cell lysate using Tri-Carb 2100TR Liquid Scintillation Analyzer counter (Packard BioScience Ltd., Pangbourne, Berkshire, U.K.). Uptake of the radiolabeled carnitine was referenced to protein concentration measured using the method of Bradford (16). 


\section{Immunoblotting and Immunohistochemistry}

Antibodies used both for immunoblot analysis and immunohistochemistry were polyclonal rabbit antibodies raised to the human MTP (gift of Dr. Bruce Middleton, University of Nottingham, Nottingham, U.K.). Immunoblot analysis of protein lysate obtained from cultured RPE cell was performed essentially as previously described (17).

For immunohistochemistry, fresh frozen retinal tissue from a 69-y-old control male was obtained at autopsy after $3 \mathrm{~h}$ postmortem delay. Skeletal muscle samples from control subjects were used as a positive control and samples from a patient with no immunodetectable MTP protein in immunoblotting was used as a negative control. Fresh frozen skeletal muscle samples were obtained by open biopsy from quadriceps femoris muscle. Skeletal muscle sections were cut at a thickness of 6 $\mu \mathrm{m}$ and retina sections at $10 \mu \mathrm{m}$. The sections were mounted on chrome gelatin-coated slides and air dried for $1 \mathrm{~h}$ before being wrapped in cling film and stored at $-20^{\circ} \mathrm{C}$ until used for immunolabeling.

Slides were air dried for a further $1 \mathrm{~h}$ and then fixed in formol-calcium for $1 \mathrm{~h}$. Endogenous peroxidase activity was inhibited by $0.6 \%$ hydrogen peroxide (vol/vol) in $80 \%$ methanol for $30 \mathrm{~min}$. To further permeabilize the sections, they were transferred to absolute ethanol for $10 \mathrm{~min}$. After washing with PBS, primary antibody (rabbit polyclonal anti-MTP) diluted 1:200 to $1: 800$ in PBS containing 1\% bovine albumin (PBS/BSA), was applied to sections for $1 \mathrm{~h}$. The sections were washed in PBS and incubated for $1 \mathrm{~h}$ with the secondary antibody (biotinylated swine anti-rabbit Ig; E0431, DAKO, Glostrup, Denmark) diluted 1:300 in PBS/BSA and applied to sections. After washing with PBS, streptavidin-biotin complex, horseradish peroxidase-conjugated (StreptABC/HRP, DAKO K0377) was applied to sections for $30 \mathrm{~min}$. Sections were washed in PBS. Peroxidase labeling was visualized using $0.05 \%$ DAB (Sigma Chemical) and $0.01 \%$ hydrogen peroxidase in $0.1 \mathrm{M}$ phosphate buffer, $\mathrm{pH} 7.3$, after $10 \mathrm{~min}$ incubation. Sections were then washed and counterstained with hematoxylin. The sections were dehydrated, cleared, and mounted in DPX (VWR International Ltd, Merck House, Poole, Dorset, UK). Some of the retina sections were placed in a bleaching solution consisting of 3\% hydrogen peroxide in $1 \%(\mathrm{wt} / \mathrm{vol})$ disodium hydrogen phosphate for $18 \mathrm{~h}$ to bleach melanin and melanin-like pigments in the RPE $(18,19)$. After washing, these sections were counterstained and mounted as above.

Methods used in securing animal tissue complied with the Association for Research in Vision and Ophthalmology statement concerning the use of animals in ophthalmic and vision research. All studies were approved by an institutional review board and all human studies were conducted with informed consent.

\section{RESULTS}

\section{Fatty Acid Oxidation Studies}

Analysis of fatty acid oxidation intermediates in the cultured RPE cells from three cell lines revealed chain shortening of $\left[\mathrm{U}-{ }^{13} \mathrm{C}\right]$-hexadecanoic acid and normal profile of acyl-carnitine ester intermediates compatible with well-functioning mitochondrial $\beta$-oxidation pathway (Fig. 1). Compared with the acylcarnitine profile in fibroblasts, peaks of long-chain acylcarnitines were less prominent but easily detectable in the RPE cells. Acetylcarnitine production was of the same degree or even more pronounced than in fibroblasts $(570.4 \pm 184.4$ $\mu \mathrm{mol} / \mathrm{U}$ of citrate synthase activity in RPE cells, $n=3$, mean $\pm \mathrm{SEM}$; and $355.0 \pm 107.3 \mu \mathrm{mol} / \mathrm{U}$ of citrate synthase activity in fibroblasts, $n=3$, mean \pm SEM). Measurement of fatty acid oxidation enzymes in the cultured RPE cells from two cell lines detected both 3-hydroxyacyl-CoA dehydrogenase (HAD) and KT activities for SC and LC substrates (LCHAD 24.64/38.27 $\mathrm{mU} / \mathrm{mg}$ protein; SCHAD 20.43/22.96 mU/mg protein; LCKT 98.55/153.08 $\mathrm{mU} / \mathrm{mg}$ protein; SCKT $81.73 / 91.85 \mathrm{mU} / \mathrm{mg}$ protein). These activities were higher than those detected in fibroblasts using the same assay method (LCHAD $12.2 \pm 1.1$,
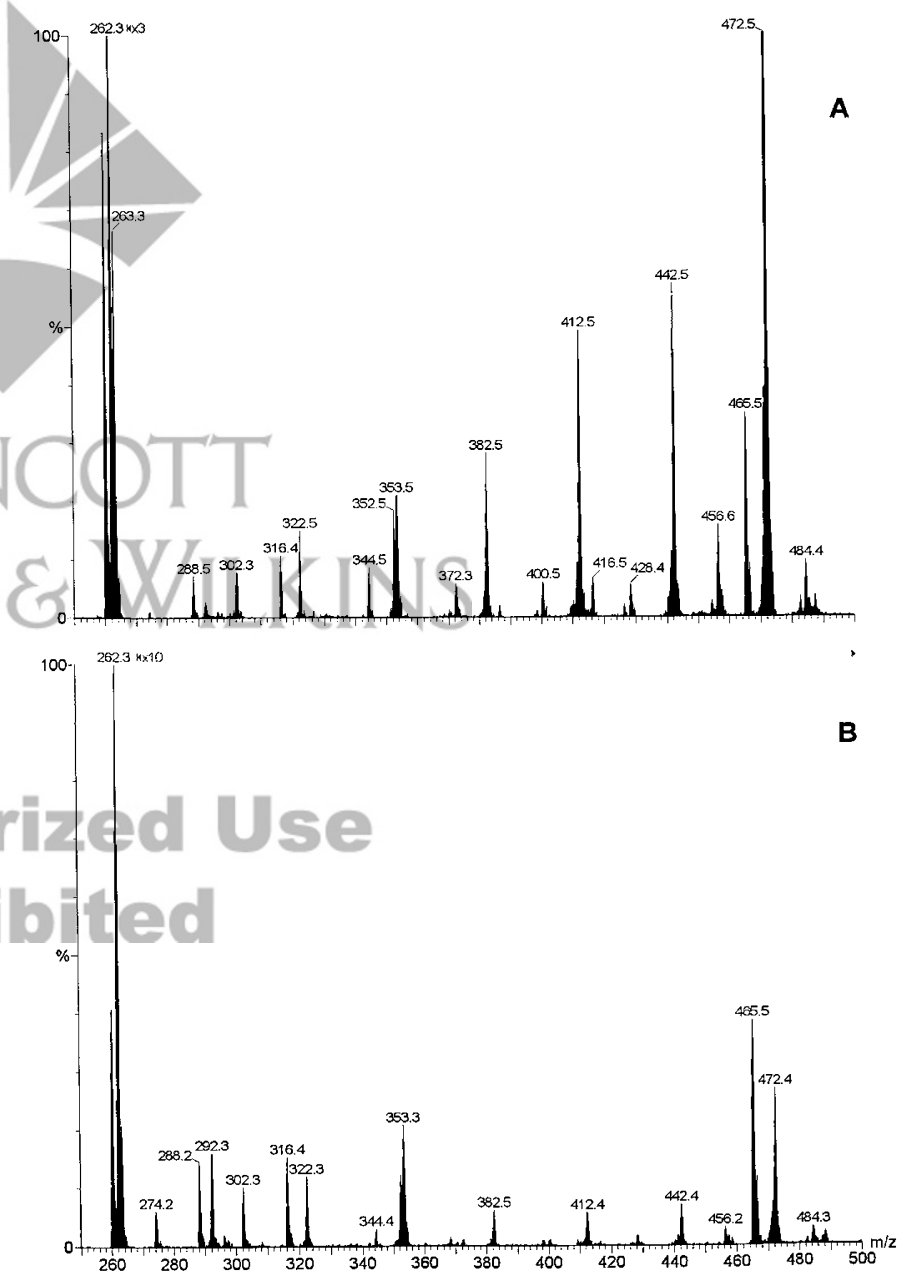

Figure 1. Acylcarnitine intermediate profiles generated by incubation of cultured control human fibroblasts $(A)$ and porcine RPE cells $(B)$ with stable isotope-labeled hexadecanoic acid and medium containing L-carnitine. The signals represent molecular ions of acylcarnitine butyl esters detected by tandem mass spectrometry. Internal standards: $\left({ }^{2} \mathrm{H}_{3}\right)$ acetylcarnitine [mass to charge ratio $(\mathrm{m} / \mathrm{z}) 263],\left({ }^{2} \mathrm{H}_{9}\right)$ octanoylcarnitine $(\mathrm{m} / \mathrm{z} 353),\left({ }^{2} \mathrm{H}_{9}\right)$ palmitoylcarnitine $(\mathrm{m} / \mathrm{z} 465)$, acetylcarnitine $(\mathrm{m} / \mathrm{z} 262)$, butyrylcarnitine $(\mathrm{m} / \mathrm{z} 292)$, hexanoylcarnitine $(\mathrm{m} / \mathrm{z} 322)$, octanoylcarnitine $(\mathrm{m} / \mathrm{z} 352)$, decanoylcarnitine (m/z 382), dodecanoylcarnitine (m/z 412), tetradecanoylcarnitine (m/z 442), hexadecanoylcarnitine $(\mathrm{m} / \mathrm{z} 472)$. For incubation and analysis conditions, see the text. 
SCHAD $6.6 \pm 0.6$, LCKT $113.6 \pm 10.7$, SCKT $51.96 \pm 6.28$ $\mathrm{mU} / \mathrm{mg}$ protein, $n=5$, mean $\pm \mathrm{SEM}$ ). Carnitine uptake studies showed that RPE cells were capable of carnitine uptake at the same degree as fibroblasts $(0.83 \pm 0.37 / 1.05 \pm 0.22$ $\mathrm{pmol} / \mathrm{min}$ per $\mathrm{mg}$ protein and $1.00 \pm 0.11 / 0.80 \pm 0.06 \mathrm{pmol} /$ min per mg protein, respectively, $n=2$, measured in triplicate, mean \pm SEM). The carnitine uptake in RPE cells and fibroblasts was similar to that detected earlier in control fibroblasts and lymphoblasts $(15,20)$.

\section{Immunoblotting and Immunohistochemistry}

Immunoblotting of RPE cell lysates revealed both $\alpha$ - and $\beta$-subunit bands of the MTP. The sizes of both subunits were similar to those in lysates of pig heart mitochondria $[87 \mathrm{kD}$ and $50 \mathrm{kD}$, respectively (not shown)] but slightly larger than in homogenates of human cells or tissue $(78 \mathrm{kD}$ and $50 \mathrm{kD}$, respectively) (Fig. 2).

In immunohistochemistry with polyclonal rabbit antibodies raised to the human MTP, skeletal muscle sections showed clear particulate immunolabeling, reflecting the different distribution of fiber types and content of mitochondria (Fig. 3). Muscle from a MTP-deficient patient showed faint background labeling only, with no mitochondrial labeling. Retinal sections showed strong labeling in photoreceptors, RPE cells, ganglion cells, and other elements containing mitochondria (Fig. 4). Sections incubated without primary antibody showed no labeling and demonstrated that virtually all pigment in the RPE was rendered colorless by the postlabeling bleaching procedure.

\section{DISCUSSION}

Our results demonstrate that cultured porcine RPE cells can oxidize hexadecanoic acid by mitochondrial $\beta$-oxidation and take up carnitine at a similar rate to fibroblasts. The presence of antigens for both $\alpha$ - and $\beta$-subunits of the MTP in the retina could be demonstrated both in cultured RPE cells by immunoblotting and in human retinal sections by immunohistochemistry. Enzyme activities of two enzymes, LCHAD and LCKT, residing in the $\alpha$ - and $\beta$-subunits of MTP, respectively, could be detected in porcine RPE cells. Immunohistochemistry showed positive labeling not only in RPE cells, but also in

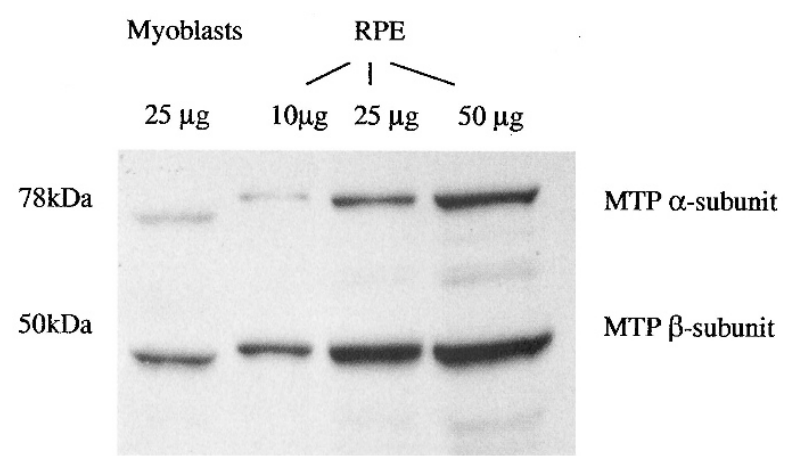

Figure 2. Immunoblot analysis of protein lysate obtained from cultured human myoblasts and porcine RPE cells with polyclonal rabbit antibodies raised to the human MTP. The slight difference in the level of the MTP bands is caused by difference in the size of the MTP in different species.
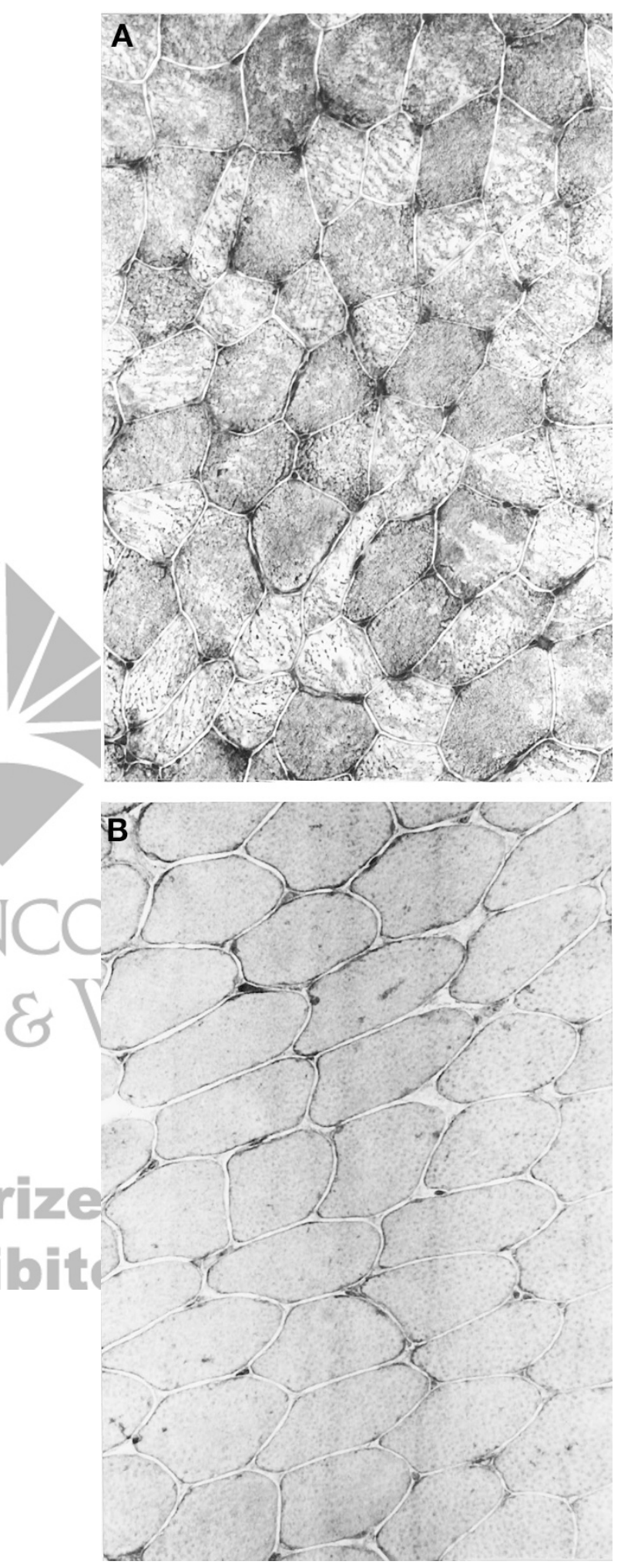

Figure 3. Immunohistochemistry of human muscle sections with polyclonal rabbit antibodies raised to the human MTP (original magnification $\times 145$ ). $(A)$ Control muscle section shows clear particulate labeling reflecting the distribution of fiber types and mitochondria. (B) A muscle section from a patient with MTP deficiency shows only faint background labeling.

photoreceptors, ganglion cells, and choroidea. The distribution of positive labeling was compatible with the distribution of mitochondria within and between different layers of the retina. 


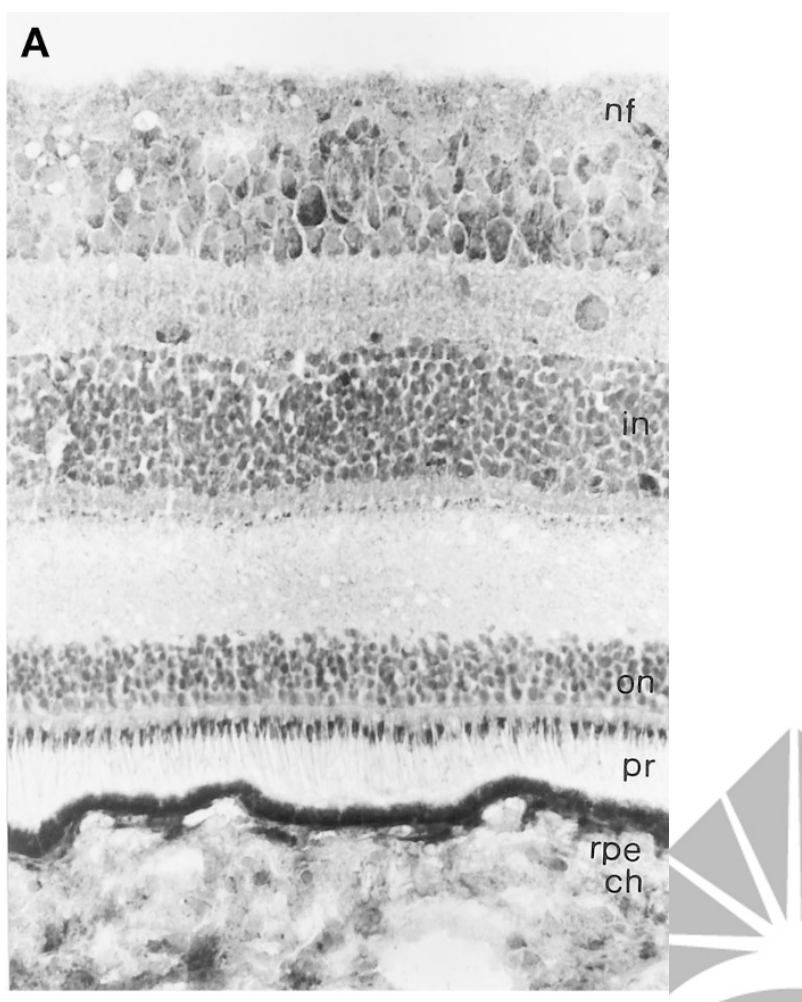

B

Glucose is the major source of metabolic energy in the retina; mannose, pyruvate, and lactate can be used as an alternative source of energy (5). It is widely accepted that fatty acid oxidation does not have any role in the energy production of the retina. Therefore, our evidence of a functional $\beta$-oxidation pathway in RPE cells and, particularly, immunohistochemical detection of the MTP, a major protein of the mitochondrial $\beta$-oxidation pathway, in photoreceptors and ganglion cells is interesting. The important role of glucose in the energy metabolism of the retina is well characterized, but in most studies individual cell layers were not analyzed separately (5). There is no work available on whether there is fatty acid oxidation in the retina and particularly in the RPE.

The oxidation of long-chain fatty acids by RPE cells suggests that all the components required for fatty acid oxidation are present in these cells. Long-chain fatty acids have to be converted to CoA esters, followed by transport into the mitochondria by the carnitine transport system. Mitochondrial fatty acid oxidation then proceeds by $\beta$-oxidation. Without all of these enzymes, we would either not have detected fatty acid oxidation at all or the pattern of intermediates would have reflected the absence of a specific component (11). Despite the presence of the enzymes, it does not mean that fatty acid oxidation occurs in vivo, inasmuch as this is dependent upon availability of substrate. While the RPE forms part of the blood-retina barrier, fatty acids and carnitine will have more access to the RPE cells than to the neural retina.

Previous studies in rat have shown that hexadecanoic acid can traverse the blood-retina barrier more efficiently than DHA, which is highly enriched in the retina (21). It has also been demonstrated that increase of L-carnitine concentration can be detected in rabbit choroid-retina and other ocular tissues, including iris and ciliary body (22). The ratio of acidsoluble acylcarnitines to free carnitine was elevated in these tissues. Because the layers of the choroidea, RPE cells, and retina were not analyzed separately, it is not known whether carnitine has access to the RPE and neural retina through the

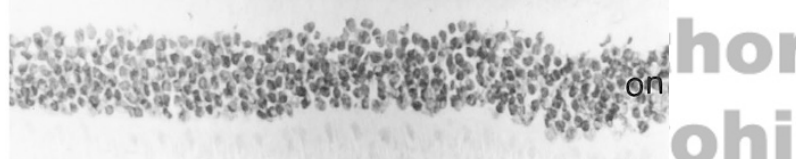

pr

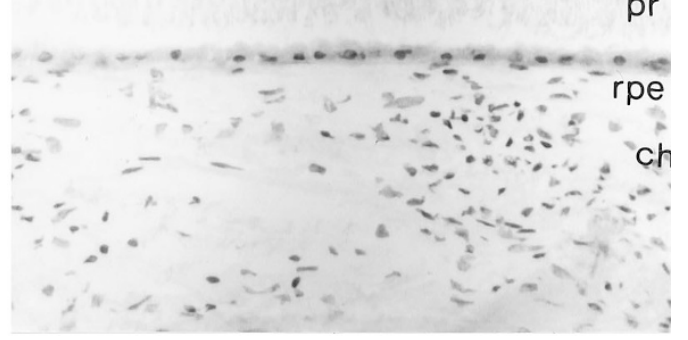

Figure 4. Immunohistochemistry of human retinal sections with polyclonal rabbit antibodies raised to the human MTP (original magnification $\times 145$ ). Sections were counterstained with hematoxylin and pigment in the RPE bleached with hydrogen peroxide. $(A)$ Strong labeling of ganglion cells, inner segments of the photoreceptors, and RPE cells. $(B)$ Section incubated without primary antibody shows no labeling. The RPE is virtually colorless. The cell layers of the retina are from the top to the bottom: nerve fiber layer $(n f)$, ganglion cell layer, inner plexiform layer, inner nuclear layer (in), outer plexiform layer, outer nuclear layer (on), photoreceptor cell layer ( $p r)$, and retinal pigment epithelium (rpe). Beneath the RPE lies choroidea (ch). choroidal endothelium. Choroidal capillaries are fenestrated, and it is apparently the choroidal endothelium that primarily restricts the access of macromolecules to the RPE and further to the neural retina $(23,24)$. As a small molecule, carnitine $\left(M_{\mathrm{r}}\right.$ 161.2) can presumably penetrate the choroidal endothelium. It was shown in rat that transfer of radiolabeled $\alpha$-aminoisobutyric acid from blood to retina by passive diffusion was higher than that into the brain (25). $\alpha$-Amino-isobutyric acid has structural similarities to carnitine and molecular weight smaller $\left(M_{\mathrm{r}} 103.1\right)$ than carnitine. Thus, it is probable that both carnitine and hexadecanoic acid have access to the RPE and possibly to the neural retina.

If retinal cells can oxidize fatty acids through mitochondrial $\beta$-oxidation pathway, why should pigmentary retinopathy be characteristic of LCHAD deficiency but not of other $\beta$-oxidation defects? The most probable explanation is that it is not the lack of metabolic energy from $\beta$-oxidation but accumulation of 3-hydroxyacyl intermediates in LCHAD deficiency that is harmful to the cells. However, it is possible that LCHAD could have additional, still unknown, roles in ocular tissues. For example, the RPE has several highly specialized functions, 
including pathways for retinoid and visual pigment metabolism, which are well but not fully characterized. Further work is required to assess the transport of carnitine through bloodretina barrier and the potential role of 3-hydroxyacyl intermediates in the pathogenesis of the retinopathy associated with LCHAD deficiency.

Acknowledgments. The authors thank Christine Hayes and Rob Taylor, Ph.D., for technical help and support.

\section{REFERENCES}

1. Tyni T, Kivelä T, Lappi M, Summanen P, Nikoskelainen E, Pihko H 1998 Ophthalmologic findings in long-chain 3-hydroxyacyl-CoA dehydrogenase deficiency caused by the G1528C mutation. A new type of hereditary metabolic chorioretinopathy. Ophthalmology 105:810-824

2. Kamijo T, Wanders RJA, Saudubray J-M, Aoyama T, Komiyama A, Hashimoto T 1994 Mitochondrial trifunctional protein deficiency — catalytic heterogeneity of the mutant enzyme in two patients. J Clin Invest 93:1740-1747

3. Tein I, Vajsar J, MacMillan L, Sherwood W 1999 Long-chain L-3-hydroxyacylcoenzyme A dehydrogenase deficiency neuropathy: response to cod liver oil. Neurology 52:640-643

4. Gillingham M, Van Clacar S, Ney D, Wolff J, Harding C 1999 Dietary management of long-chain 3-hydroxyacyl-CoA dehydrogenase deficiency (LCHADD). A case report and survey. J Inherit Metab Dis 22:123-131

5. Berman E 1991 Biochemistry of the Eye. Plenum Press, New York, pp 309-406

6. Tyni T, Kivelä T, Pihko H 1998 Ophthalmic pathology in long-chain 3-hydroxyacylCoA dehydrogenase deficiency. Curr Eye Res 17:551-559

7. Harding C, Gillingham M, van Calcar S, Wolff J, Verhoeve J, Mills M 1999 Docosahexaenoic acid and retinal function in children with long-chain 3-hydroxyacyl-CoA dehydrogenase deficiency. J Inherit Metab Dis 22:276-280

8. Edwards R 1982 Culture of mammalian retinal pigment epithelium and neural retina. Methods Enzymol 81:39-42

9. McKay B, Burke J 1994 Separation of phenotypically distinct subpopulations of cultured human retinal pigment epithelial cells. Exp Cell Res 213:85-92
10. Grisanti S, Guidry C 1995 Transdifferentiation of retinal pigment epithelial cells from epithelial to mesenchymal types. Invest Ophthalmol Vis Sci 36:391-404

11. Tyni T, Pourfarzam M, Turnbull DM 2002 Analysis of mitochondrial fatty acid oxidation intermediates by tandem mass spectrometry from intact mitochondria prepared from homogenates of cultured fibroblasts, skeletal muscle cells, and fresh muscle. Pediatr Res 52:64-70

12. Schaefer J, Pourfarzam M, Bartlett K, Jackson S, Turnbull D 1995 Fatty acid oxidation in peripheral blood cells: characterization and use for the diagnosis of defects of fatty acid oxidation. Pediatr Res 37:354-360

13. Shepherd D, Garland P 1973 Citrate synthase from rat liver. Methods Enzymol 13:11-16

14. Eaton S, Middleton B, Bartlett K 1998 Control of mitochondrial $\beta$-oxidation: sensitivity of the trifunctional protein to $[\mathrm{NAD}+] /[\mathrm{NADH}]$ and [acetyl-CoA] $/[\mathrm{CoA}]$. Biochim Biophys Acta 1429:230-238

15. Treem W, Stanley C, Finegold D, Hale D, Coates P 1988 Primary carnitine deficiency due to a failure of carnitine transport in kidney, muscle, and fibroblasts. N Engl J Med 319:1331-1336

16. Bradford M 1976 A rapid and sensitive method for the quantification of microgram quantities of protein utilizing the principle of protein dye binding. Anal Chem $72: 248-254$

17. Jackson S, Schaefer J, Middleton B, Turnbull DM 1995 Characterisation of a novel enzyme of human fatty acid beta-oxidation: a matrix-associated, mitochondrial 2-enoyl-CoA hydratase. Biochem Biophys Res Commun 214:247-253

18. Fuchs U, Kivelä T, Tarkkanen A 1991 Cytoskeleton in normal and reactive human retinal pigment epithelial cells. Invest Ophthalmol Vis Sci 32:3178-3186

19. Romeis B 1968 Mikroscopische Technik, 16th Ed. R. Oldenbourg Verlag, Munich, p 281

20. Tein I, Xie Z-W 1996 The human plasmalemma carnitine transporter defect is expressed in cultured lymphoblasts: a new non-invasive method for diagnosis. Clin Chim Acta 252:201-204

21. Alberghina M, Lupo G, Anfuso C, Infarinato S 1994 Differential transport of docosahexaenoate and palmitate through the blood-retina and blood-brain barrier in the rat. Neurosci Lett 171:133-136

22. Pessotto P, Valeri P, Arrigoni-Martelli E 1994 The presence of L-carnitine in ocular tissues of the rabbit. J Ocul Pharmacol 10:643-651

23. Essner E, Gordon S 1983 Observations on the permeability of the choriocapillaris of the eye. Cell Tissue Res 231:571-577

24. Törnqvist P, Alm A, Bill A 1990 Permeability of ocular vessels and transport across the blood-retinal barrier. Eye 4:303-309

25. Stewart P, Tuor U 1994 Blood-eye barriers in the rat: correlation of ultrastructure with function. J Comp Neurol 340:566-576

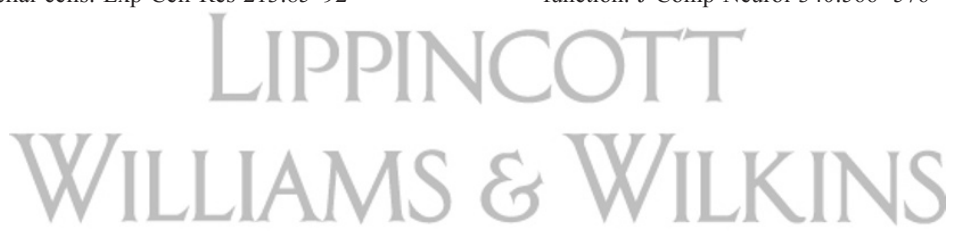

